\title{
MÉTODO DE CASO COMO FERRAMENTA DE ENSINO PARA INTEGRAÇÃO ENTRE A TEORIA ACADÊMICA E A PRÁTICA EMPRESARIAL
}

\section{CASE METHOD AS A TEACHING TOOL FOR INTEGRATION BETWEEN ACADEMIC THEORY AND BUSINESS PRACTICE}

\author{
MÉTODO DE CASO COMO HERRAMIENTA DE ENSEÑANZA PARA LA \\ INTEGRACIÓN DE LA TEORÍA ACADÉMICA Y LA PRÁCTICA EMPRESARIAL
}

Elizângela Silva Almeida*

Flávia Angeli Ghisi Nielsen ${ }^{* *}$

Ivete Rodrigues ${ }^{* *+}$

Leandro José Morilhas

Rodolfo Leandro de Faria Olivo

Fábia Auxiliadora Pereira de Mattos Spadoto

\begin{abstract}
Resumo: Partindo de uma reflexão sobre o processo de ensino-aprendizagem nos cursos de Administração, principalmente no que se refere ao emprego de recursos pedagógicos que aproximem os alunos da realidade a ser enfrentada nas organizações, este estudo investiga o "Método do Estudo de Caso" como disciplina na grade curricular em uma das principais instituições de ensino superior em Administração de Empresas do Brasil. Para obtenção dos resultados da pesquisa, o estudo foi estruturado em três etapas: entrevista qualitativa com docente das disciplinas Resolução de Casos I e II na instituição objeto de estudo, um estudo observacional nas aulas das disciplinas e um questionário quantitativo com alunos da graduação para analisar a percepção dos estudantes quanto ao emprego desse método em uma disciplina regular do curso de Administração. Os resultados indicam que o método de caso promove maior integração entre a teoria e a prática, na medida em que os alunos são colocados no papel de gestores e têm que tomar decisões de negócio considerando o complexo mundo empresarial, aproximando-os da vivência no ambiente organizacional.
\end{abstract}

Palavras chaves: Ensino da administração. Método de caso. Metodologias de ensino-aprendizagem.

\footnotetext{
*Graduada em Administração pela Faculdade FIA de Administração e Negócios E-mail: flaghisi@gmail.com

** Doutora em Administração pela Universidade de São Paulo. Professora do curso de Mestrado Profissional em Gestão de Negócios da Faculdade FIA de Administração e Negócios. E-mail: flaghisi@gmail.com

*** Doutora em Administração pela Universidade de São Paulo. Professora Adjunta da Faculdade FIA de Administração e Negócios. E-mail: iveterod@gmail.com

***** Doutor em Administração pela Universidade de São Paulo. Coordenador de Pós-Graduação, Pesquisa e Extensão; Professor do curso de Mestrado Profissional em Gestão de Negócios da Faculdade FIA de Administração e Negócios. E-mail: leandrom@fia.com.br

***** Doutor em Administração pela Universidade de São Paulo. Professor do curso de Mestrado Profissional em Gestão de Negócios da Faculdade FIA de Administração e Negócios. E-mail: rodolfo.olivo@outlook.com

******* Mestre em Administração pela Pontifícia Universidade Católica de São Paulo. Coordenadora de Cursos de MBA da Faculdade Fia de Administração e Negócios. E-mail: flaghisi@gmail.com
} 


\begin{abstract}
Starting from a reflection on the teaching- learning process in administration courses regarding to the use of pedagogical resources that approach the students of reality to be faced in organizations, this study investigates the "case study method" as a discipline in the curriculum at one of the leading institutions of business administration course in Brazil's higher education. To obtain the results of the research, the study was structured in three stages: qualitative interview with the teacher of the disciplines Case Resolution I and II in the study object institution, an observational study in classes of each discipline and a quantitative survey with the undergraduate students to analyze their perception regarding the use of this method in a regular discipline of business administration course. The results indicate that the case method promotes greater integration between theory and practice in that the students are placed in the role of managers and have to take business decisions considering the complex business world, exposing them to the experience in the organizational environment.
\end{abstract}

Keywords: Teaching administration. Case method. Teaching-learning methodologies.

Resumen: Partiendo de una reflexión sobre el proceso de enseñanza-aprendizaje en los cursos de administración, principalmente en lo que se refiere al empleo de recursos pedagógicos que aproximen los alumnos a la realidad a ser enfrentada en las organizaciones, este estudio investiga el Método del Estudio de Caso como asignatura en la grade curricular en una de las principales instituciones de enseñanza superior en administración de empresas de Brasil. Para obtención de los resultados de la pesquisa, el estudio fue estructurado en tres etapas: entrevista cualitativa con docente de las asignaturas Resolución de Casos I y II en la institución objeto de estudio, un estudio observacional en las clases de las asignaturas y un cuestionario cuantitativo con alumnos de la graduación para analizar la percepción de los estudiantes cuanto al empleo de ese método en una asignatura regular del curso de administración. Los resultados indican que el método de caso promueve mayor integración entre la teoría y la práctica, en la medida en que los alumnos son colocados en el papel de gestores y tienen que tomar decisiones de negocio considerando el complexo mundo empresarial, aproximándoles de la vivencia en el ambiente organizacional.

Palabras claves: Enseñanza de la administración. Método de caso. Metodologías de enseñanzaaprendizaje.

\section{Introdução}

De acordo com Nicolini (2003), Closs, Arambaru e Antunes (2009), o ensino chamado de tradicional, fundamentado na metodologia de aceitar e memorizar o conteúdo, impossibilita que os alunos usem a criatividade para resolver problemas, não contribui na percepção acerca de um fenômeno administrativo e desestimula a visão crítica das teorias que lhes são ensinadas. Freire (2014) critica e recusa o modelo "bancário" meramente transferidor de conteúdo que, segundo ele, deforma a necessária criatividade tanto do educando quanto do educador. Vencer o tradicionalismo pedagógico implica a presença de educadores e educandos criadores, instigadores e inquietos.
Coto, Neto e Pacheco (2009) complementam essa visão ao afirmarem que, no ensino tradicional, baseado somente na transmissão de saberes pelos professores, o aluno é passivo durante todo processo de aprendizagem. Para os autores, esse método de ensino não consegue desenvolver estudantes com "[...] coragem para correr riscos e habilidades para resolver novos problemas.” Além disso, segundo Bono (2000, apud COTO; NETO; PACHECO, 2009), os estudantes devem ser preparados para inovar e desenvolver um pensamento construtivo.

No ensino superior, a ênfase deve ser dada às ações dos alunos, e a aprendizagem deve estar centrada na participação e parceria 
dos próprios educandos, a fim de incentivá-los e motivá-los em relação ao conhecimento. (MASETTO, 2012). O professor não deve ser um obstáculo. Pelo contrário, nas palavras de Freire (2014, p. 28), “[...] na verdadeira aprendizagem os educandos vão se transformando em reais sujeitos da construção e reconstrução do saber ensinado, ao lado do educador, igualmente sujeito do processo.” Masetto (2012) defende que trabalhar com pesquisa, projetos e novas tecnologias são caminhos que podem incentivar e facilitar o desenvolvimento da parceria e a coparticipação entre professor e aluno. As técnicas mais eficazes para o sucesso do processo de ensino-aprendizagem são as dinâmicas de grupo, estratégias participativas, técnicas que colocam os alunos em contato com a realidade.

No que tange ao ensino da Administração, faz-se necessária uma ferramenta pedagógica que deixe os alunos o mais próximo possível do que será enfrentado nas organizações, que os faça desenvolver o senso crítico e amplie seus conhecimentos. Diante desse cenário, o método do estudo de caso como ferramenta pedagógica vem sendo adotado por algumas instituições de ensino para ensinar a complexidade dos mais diversos problemas de gestão, trazendo-os próximos da realidade, para que os alunos se coloquem no papel de gestores. O método vem ganhando força em função das transformações aceleradas no campo das profissões, em que a capacidade de resolução de problemas é fundamental para os novos perfis profissionais.

Atentando-se a essa orientação, destaca-se cada vez mais a necessidade de diminuir a distância entre o que é ensinado na sala de aula e a prática no ambiente organizacional. Roesch (2007, p. 12) destaca que “[...] o caso para ensino é um entre poucos métodos de ensino-aprendizagem que possibilita um casamento entre teoria e prática, tão necessário para a área de Administração.” Enquanto
Lima (2003) enfatiza que, como ferramenta pedagógica, o estudo de caso é o que melhor atende ao princípio construtivista de aprendizagem, propiciando um aprendizado mais ativo, reflexivo, colaborativo.

Na maioria das instituições de ensino, os casos são explorados de forma transversal. Segundo Iizuka (2008), muitos deles são encontrados em livros didáticos de Administração, mas raramente retratam a realidade brasileira. Dificilmente são trabalhados casos que discutem a gestão de forma integrada, trazendo para sala de aula relatos sobre os desafios, oportunidades e as situações vividas nas organizações.

Diante desse contexto, o presente estudo irá explorar exatamente um caso de uma Instituição de Ensino Superior (IES), que passou a incluir em sua grade curricular uma disciplina específica que trabalha com a resolução de casos que retratem a realidade das organizações. Os resultados deste estudo podem servir de base para outras IES que almejam inserir em suas grades curriculares uma disciplina que utilize exclusivamente o método de caso como ferramenta de ensino.

\section{Conceituando caso}

Menezes (2009) afirma que a proximidade dos termos estudo de caso e método pode, casualmente, levar a uma confusão conceitual. O primeiro é uma estratégia metodológica para se conduzir uma pesquisa empírica, exigindo uma preparação prévia por parte do pesquisador e a organização de um planejamento da pesquisa. Pode ser utilizada em diversos campos de pesquisa, tais como na ciência política, na administração pública e de empresas, na psicologia e sociologia, dentre outros.

O segundo, método do caso, refere-se à ferramenta pedagógica utilizada, de maneira 
geral, na educação de advogados, médicos, juristas e administradores, dentre outros profissionais. No método do caso os estudantes confrontam a teoria com a prática a partir de situações reais. Apesar de ainda ser inovadora, essa técnica didática possui uma longa trajetória, tendo nascido, efetivamente, nos fins do século XIX. É necessário ficar claro que o método do caso não se constitui de fatos fictícios. A análise ocorre a partir de casos reais. (MENEZES, 2009).

Segundo Ellet:

Casos são representações da realidade que colocam o leitor no papel de participante da situação. A sua unidade de análise varia consideravelmente, desde um único indivíduo ou organização a toda uma nação ou mesmo ao mundo. Sua exposição pode se estender de uma página a cinquenta ou mais, embora todos tenham um propósito em comum: representar a realidade, descrever uma situação com todos os fatos transversais e delimitações - incluindo impropriedades, questões secundárias, falsos juízos e informações incompletas ou em quantidade demasiada. (ELLET, 2008, p. 21).

As situações reais de negócio são fluidas. Há aspectos do problema que são claros; porém, há aspectos confusos e dúbios. Há informações excessivas, mas há também, em outros momentos, insuficientes. Os casos pretendem retratar essa fluidez. Ellet (2008) afirma que a prática de trabalhar na resolução de casos que retratam a realidade no mundo empresarial oferece aos estudantes o equivalente aos laboratórios utilizados para ensinar cientistas e médicos, uma vez que a teoria é colocada em prática. Para cumprir essa função, um caso deve fazer analogia com a realidade e ser substituto da experiência direta de uma situação de negócio. Nesse sentido, para esse autor, um caso deve apresentar três características fundamentais: tratar de uma questão ou mais questões empresariais significativas, discutir informações suficientes para embasar conclusões e não apresentar conclusões já manifestas.

A leitura de um caso precisa ser atenta, uma vez que são exigidos leitores mais ativos, que estejam prontos para indagar questões sobre o dilema apresentado, leitores que questionem e tenham um senso crítico aguçado para discutir e debater opiniões.

Os casos mais comuns e utilizados são os Casos Harvard ou Clássicos, que apresentam essa denominação porque a universidade americana foi pioneira na utilização desse método de ensino. Foram desenvolvidos conforme uma filosofia de ensino e mantêm até os dias de hoje suas características originais. Inicialmente, foram adotados na Escola de Direito, no final do século XIX, e modificou-se radicalmente a metodologia de ensino norte-americana. Antes deles, os estudantes memorizavam a matéria sistematicamente apresentada nos manuais de Direito. A mudança foi radical: da memorização para a análise dos casos. Também na área de administração a escola americana foi pioneira. A Harvard Business School introduziu o método na área de administração no início do século XX. (CONVERSE, 1945 apud IKEDA; VELUDO-DE-OLIVEIRA; CAMPOMAR, 2006; MENEZES, 2009).

Já os Casos Vivos retratam uma tipologia especial de caso. "Consistem de informações sobre fatos ou situações que se sucederam há pouco tempo ou que ainda estão ocorrendo. Os palestrantes que os apresentam são pessoas diretamente relacionadas ao caso, conhecedores de sua origem, detalhes, evolução etc. Os casos vivos também têm a vantagem de poder ser acompanhados concomitantemente ao desenrolar dos fatos, o que traz implicações positivas à aprendizagem." (NUÑEZ, 2003; KENNEDY et al., 2001 apud IKEDA; VELUDO-DE-OLIVEIRA; CAMPOMAR, 2006, p. 149). 


\section{Procedimentos metodológicos}

A pesquisa empírica utilizou como estratégia metodológica o estudo de caso único. O maior conhecimento sobre casos particulares oportuniza ajustes em entendimentos cristalizados a respeito de uma determinada realidade. É possível ainda que o caso seja utilizado como mecanismo de interpretação e geração de significado nas organizações, por meio da construção de interpretações compartilhadas, conhecimento válido e aumento do desempenho organizacional. (ZANNI et al., 2011).

A unidade de análise escolhida foi a Faculdade FIA de Administração e Negócios (FFIA), instituição de ensino superior localizada no município de São Paulo, capital do Estado de São Paulo, em função da grande preocupação que essa instituição possui com a educação e com o profissional que está começando sua atuação executiva dentro das organizações. O modelo do curso de graduação oferecido pela Faculdade FIA busca preparar melhor esse profissional, utilizando metodologias de ensino que propiciem deixá-lo mais próximo do que é vivenciado no ambiente organizacional.

A faculdade é mantida pela Fundação Instituto de Administração, pessoa jurídica de direito privado sem fins lucrativos, constituída em 10 de junho de 1980 e oferta serviços educacionais com padrão de excelência. (FIA, 2011, p. 07). Pelo compromisso com a qualidade de seus cursos e corpo docente, a instituição aparece frequentemente em rankings internacionais. O seu MBA Executivo foi eleito pelo jornal britânico Financial Times (2011) como o 25 melhor das Américas, o único de uma instituição brasileira que aparece nesta classificação. A instituição também recebeu o importante título de "Escola mais inovadora da América do Sul”, pela European CEO, publicação realizada em um editorial composto por jornalistas e correspondentes dos veículos mais influentes do mundo em 2014. A Fundação também foi listada no ranking da Revista Você S/A em 2010 com os melhores MBAs do Brasil, liderando várias categorias pesquisadas para o ranking.

A Faculdade FIA oferece o curso superior em Administração com duração de oito semestres, sendo que os quatro primeiros são ministrados em período integral, e oferta cinquenta vagas por semestre. Seu corpo docente é composto por professores com nível de mestrado e doutorado em Administração e áreas relacionadas, que contam com experiências na docência em cursos de MBA e pós-graduação lato sensu oferecidos pela FIA. Para obtenção dos dados, o estudo de caso foi estruturado em três etapas combinando instrumentos de coleta que permitem obter uma visão ampla do fenômeno estudado: a) entrevista qualitativa com docente das disciplinas Resolução de Casos I e II na instituição objeto de estudo, b) um estudo observacional nas aulas das disciplinas e c) um questionário quantitativo com alunos da graduação para analisar a percepção dos estudantes quanto ao emprego desse método em uma disciplina regular do curso de administração.

$\mathrm{Na}$ primeira etapa foi realizado um levantamento qualitativo por meio de uma entrevista semiestruturada, cujo objetivo principal foi analisar como se deu a implementação das disciplinas Resolução de Casos I e II na instituição objeto de estudo (a Faculdade FIA de Administração), analisando a forma como ela foi estruturada e como é atualmente ministrada. A entrevistada, que há 4 anos é a professora responsável pela disciplina, assumiu e reformulou a estrutura e seu formato.

Na segunda etapa foi empregada a observação com objetivo de capturar informações, percepções e comportamentos em tempo real do fenômeno estudado. A amostra foi selecionada de forma aleatória, na qual foram escolhidas duas aulas da disciplina Resolução 
de Casos, ministradas pela docente que foi entrevistada na primeira etapa descrita acima.

Por fim, na terceira etapa foi utilizado um questionário com 19 questões, sendo 16 fechadas e 3 abertas, que teve como principal objetivo extrair a percepção dos alunos quanto à metodologia de ensino baseada no método de caso. $\mathrm{O}$ campo de amostragem se delimitou aos alunos da graduação em Administração da Faculdade FIA do $3^{\circ}$ ao $8^{\circ}$ semestre, que tiveram as disciplinas de Resolução de Casos I e II. Os dados foram coletados em seis turmas da graduação, com uma média aproximada de 20 alunos por turma, totalizando 84 respondentes.

O objetivo da utilização dos três instrumentos de coleta de dados foi proporcionar melhor qualidade das informações coletadas por meio da triangulação de fontes de evidência, de modo que o estudo de caso ganhasse maior profundidade.

\section{Análise dos resultados}

\section{Implementação do método de caso}

Nesta primeira etapa o objetivo principal consistiu em analisar o processo de implementação das disciplinas Resolução de Casos I e II na Faculdade FIA de Administração, reunindo informações de como elas foram estruturadas e ministradas.

Em junho de 2013, a docente entrevistada foi convidada para assumir as disciplinas Resolução de Casos de Gestão I ( $3^{\circ}$ semestre) e II ( $4^{\circ}$ semestre) na graduação em Administração de Empresas da Faculdade FIA. A ementa da disciplina permitia certa flexibilidade no seu conteúdo, e a professora, durante dois meses, concentrou-se no planejamento das atividades que seriam desenvolvidas e na dinâmica das aulas.

Após análise em periódicos e livros de docência no ensino superior, a docente optou por mesclar casos de gestão teóricos (Harvard, GV, ESPM, etc.) e Casos Vivos, pelas seguintes razões:

- possibilidade de discussão de casos internacionais (a maioria dos casos teóricos) e brasileiros (casos vivos), esses últimos mais próximos da realidade e conhecimento dos alunos;

- possibilidade de discussão de casos reais e análise de problemas que de fato as empresas enfrentaram ou ainda enfrentam, sendo contados pelos próprios executivos que vivenciaram ou vivenciam tais situações (casos vivos);

- possibilidade de discussão com executivos de mercado na sala de aula, que enfrentaram ou enfrentam tais problemas, aproximando a teoria da prática, na percepção dos alunos, e motivando-os no envolvimento e análise dos casos.

Durante a entrevista a docente reforçou:

Eu fiz graduação em administração em uma das principais instituições de ensino do Brasil e referência internacional. Mesmo assim, quando saí da faculdade, sentia-me despreparada para enfrentar a vida real. Ainda que tenha estudado diversos casos na graduação, a maioria eram teóricos de empresas internacionais e que nem sempre eu as conhecia. Ou então eram casos conhecidos, mas com problemas fictícios. Mesmo tendo feito alguns estágios, também não sentia segurança para lidar com problemas complexos, porque nem sempre as atividades envolvidas exigiam muita reflexão e capacidade analítica [...] Na verdade o objetivo maior da graduação é dar o instrumental ao aluno, apresentar os principais conceitos teóricos; de todo modo, a aplicação não deve ser esquecida ou deixada para 
segundo plano, porque no final das contas, estamos preparando futuros profissionais para trabalharem em empresas, administrarem negócios e enfrentarem situações que exigirão lidar com múltiplos desafios. Passados anos depois de minha formação, tendo estudado muito e exercido funções no meio empresarial, cheguei à conclusão que a academia precisa criar alternativas para tornar o ensino mais dinâmico, prático, minimizando o distanciamento entre a teoria e a prática [...] De alguma forma, tentei implementar nessa disciplina, com o aval da coordenação da escola, esse olhar mais prático. Trouxe casos de Harvard, reais, porém distantes geográfica e temporalmente, entre outros teóricos do gênero para discussão, mas também casos reais contemporâneos, apresentados por executivos que vivenciam aqueles problemas apresentados em sala. Muitos deles ainda no momento da apresentação não têm as respostas para aqueles desafios. E isso acaba motivando muito os alunos, que acabam entrando na vida real do executivo. E, de acordo com a dinâmica que fazemos em sala, eles têm uma semana para pensar, analisar, fazer pesquisa de mercado na tentativa de encontrar algumas saídas para o problema apresentado. Muitas vezes as ideias dos alunos são tão interessantes, que poderiam de fato serem implementadas pelo executivo. Essa é a ideia. (ENTREVISTA REALIZADA, 2015).

Para a elaboração da dinâmica dos casos vivos, a docente contou com a ajuda de diversos executivos. Pelo fato de também ministrar aulas no MBA e Mestrado, além de exercer função executiva na própria instituição, na gestão comercial com empresas de médio e grande porte, a docente tinha fácil acesso aos executivos que poderiam apresentar o caso na graduação.

Desde que a docente assumiu as disciplinas Resolução de Casos de Gestão I e II em 2013, vinte e oito (28) executivos estiveram na instituição apresentando seus casos.
Alguns deles o apresentaram novamente nos semestres seguintes para diferentes turmas.

Para a docente, planejar o cronograma das atividades com antecedência foi fator crucial para o sucesso da disciplina. Um mês antes das aulas começarem, ela já tinha todos os casos agendados. No primeiro dia do curso apresentava o plano de aula, o cronograma dos casos teóricos e vivos e já fazia a divisão dos casos entre os grupos. Em uma turma de 20 alunos (média de alunos por turma) eram formados por volta de 6 a 7 grupos.

No primeiro dia de aula eu apresentava os casos que iríamos ver ao longo da disciplina, mas deixava claro que esses poderiam mudar, já que eu dependia da agenda complicada desses executivos. Em 2015, por exemplo, não sei se foi coincidência ou não com a crise econômica brasileira, mas praticamente todos os executivos agendados em uma das turmas me ligaram para mudar ou cancelar sua participação. Em uma noite um deles teve um problema de saúde, me ligou por volta das 22:00 horas do dia anterior dizendo que não tinha condições de apresentar o caso. Mas depois ele conseguir ir, para a minha sorte. E eu estava muito preocupada, pois tinha ligado para vários conhecidos mais próximos e ninguém podia comparecer já no dia seguinte. Em uma outra situação, outro executivo me ligou um dia antes dizendo que tinha tido um problema sério na empresa e não poderia se ausentar. Tive que acionar minha rede de contatos, mas ainda bem que consegui um substituto. Até hoje não tive um caso cancelado. Em algumas turmas, não tive problema algum, isso é, o cronograma foi seguido integralmente com a sugestão de casos do início do semestre. De todo modo, aprendi, com a experiência de quase três anos ministrando essa disciplina, que tenho que ter sempre alguma carta na manga, um plano B, em caso de necessidade de substituição imediata de um palestrante. (ENTREVISTA REALIZADA, 2015). 
Quando assumiu a disciplina, a docente tinha receio de não conseguir executivos predispostos a apresentarem seus casos à graduação. Mas, como dito anteriormente, ela possuía uma ampla rede de contatos, e muitos deles tinham vontade e interesse em compartilhar um pouco do seu conhecimento com estudantes em início de carreira. A cada convite era explicada a estrutura (roteiro) e dinâmica da aula:

- Estrutura da apresentação do Caso Vivo - a apresentação deveria ser feita em powerpoint e se aproximar do seguinte roteiro:

a. Apresentação da empresa: números (unidades, locais de atuação, funcionários, dados de mercado, produtos comercializados, público alvo, etc), apresentação de vídeo institucional, no caso de ajudar a entender melhor o caso.

b. Apresentação do cenário de mercado: economia, concorrentes, competição, mercado internacional, negócio atual da empresa.

c. Apresentação de dados específicos do caso: dados do caso propriamente dito, apresentação do caso e problema central a ser analisado.

d. Fechamento do caso com as questões chaves para discussão: três (3) a cinco (5) perguntas chave para os alunos refletirem e discutirem, inicialmente fora da sala de aula, por uma semana.

- Dinâmica da Apresentação do Caso Vivo:

a. A apresentação era feita em uma hora e vinte pelo executivo. Os alunos poderiam interagir a qualquer momento. Nos 10 minutos finais, abria-se a sessão para as perguntas dos alunos (dúvidas/curiosidades).

b. O último slide da apresentação envolvia as questões chave para discussão - perguntas não óbvias, de difícil resposta, questões-problema que a empresa enfrenta ou enfrentou. Os alunos tinham uma (1) semana para levantar informações adicionais sobre o caso, pesquisar lojas, fazer pesquisa de campo, etc.

c. A discussão do caso em sala só ocorria após uma semana da apresentação feita pelo executivo. Às vezes ele retornava e participava da discussão em conjunto com a professora e alunos da turma. Em outros momentos, a própria professora conduzia a plenária, sem a participação do executivo.

O processo de aprendizagem dos casos vivos envolvia três estágios: 1) Preparação Individual, 2) Discussão em Grupos e 3) Discussão em Plenária. Após a apresentação do caso pelo executivo, os alunos tinham que trabalhar individualmente (preparação individual) e, posteriormente, em grupo (discussão em grupos), por uma semana para resolver os problemas apresentados. Essa discussão (individual e entre os integrantes do grupo) era fundamental para: ampliar o “campo de visão"; possibilitar a análise sob novas perspectivas; ter um entendimento coletivo do caso.

Todos os grupos deveriam entregar na semana seguinte um relatório do caso, seguindo a estrutura passada em sala pela professora nos cinco primeiros minutos de aula:

1. Descrição do contexto - qual o dilema do caso?;

2. Resumo - lista das informações importantes do caso; 
3. Alternativas possíveis - que a equipe entende que poderiam resolver o dilema;

4. Decisão do grupo sobre o dilema e argumentos para embasar a decisão.

Embora todos os grupos devessem entregar um relatório, apenas um deles era escolhido para apresentar o caso. A distribuição dos casos entre os grupos era feita no primeiro dia de aula, então todos sabiam quando teriam que fazer suas apresentações.

Na aula seguinte à apresentação do caso pelo executivo, o grupo selecionado tinha quarenta minutos para relatar o caso, trazendo informações adicionais. Para a resolução do caso era necessário o uso de fontes múltiplas: pesquisas de campo com executivos, consumidores, levantamento em dados secundários, pesquisa em estabelecimento/ lojas, análise de dados econômicos e financeiros, uso de fórmulas/teorias vistas em outras aulas do curso. Isso era necessário para a resolução do caso em questão.

Durante a apresentação do grupo em sala (discussão em plenária), a professora envolvia os demais grupos para que também apresentassem suas opiniões e ideias. Essa etapa tinha os seguintes objetivos: a) entendimento completo e minucioso do caso; b) aprendizado além do nível alcançado na preparação individual ou na discussão em grupo.

No processo de aprendizagem do estudo de caso, o professor e os alunos assumem papéis distintos:

- Aluno: papel de protagonista - agente ativo no processo de aprendizagem. Deve ter postura responsável para os estudos, se preparando com antecedência;

- Professor: papel de moderador - deve estimular e instigar o raciocínio dos alunos, intermediando as discussões e o raciocínio analítico. Exerce o papel de “advogado do diabo", mantendo o foco e fazendo avançar a discussão. Não é sua tarefa ajudar a classe a atingir um consenso, já que existem diferentes percepções de mundo e diversas formas de se resolver um problema de gestão.

\section{Comportamento e atitudes de alunos e docentes durante a discussão do caso}

Com o estudo observacional realizado na segunda etapa, foi possível capturar informações e comportamentos dos alunos e professor sob a utilização do método de caso como ferramenta de ensino.

A observação foi feita em duas partes; na primeira etapa foi feita uma imersão inicial, na qual foi registrado o que foi considerado apropriado para este estudo.

\section{a) Parte 1: Imersão Inicial}

Nesta imersão, foi possível relacionar os fatos observados com as características do caso vivo apresentadas pela literatura.

Episódio: Aula de Resolução de Casos - Apresentação do Caso Vivo Santa Dose

Data/Horária: 29 de maio de 2016/ Hora: $10 \mathrm{~h}$ às $11 \mathrm{~h} 40$

Participantes: Alunos da graduação em Administração, professora e palestrante convidado

Local: Faculdade FIA de Administração

O caso vivo apresentado nesse dia foi o da Santa Dose, uma marca de cachaça aromatizada, que é um produto fácil de beber devido ao baixo teor alcoólico, com receita que reúne 4 elementos: cachaça de alambique, que é envelhecida de 3 a 5 anos, em barril de carvalho, combinada com mel e limão naturais. O caso 
foi apresentado pela gestora que gerencia as principais marcas da Brown-Forman.

A palestrante começa a apresentação fazendo uma descrição do mercado de destilados, especificações da categoria de cachaça e história da criação do produto. Além disso, a palestrante também fez uma descrição detalhada do público alvo da empresa, trazendo vários dados sobre esse público, como: perfil, sexo, idade e classe social. Também foram apresentadas as estratégias de comunicação da empresa, objetivos da marca e meios de sua consolidação no mercado de destilados.

Ao final da apresentação do caso, a palestrante deixou três perguntas para nortear os alunos, alternativas que poderiam ajudar a empresa a enfrentar os atuais dilemas em relação aos seus concorrentes, aumentar sua participação de mercado e possíveis estratégias de comunicação e divulgação para alcançar de forma mais efetiva seu público-alvo.

Com essa imersão inicial foi possível evidenciar, na observação, algumas das características apresentadas pela literatura. A modalidade de caso vivo é um tipo de caso que traz grandes vantagens ao aprendizado, pois os alunos acompanham a evolução e história do caso concomitantemente com o desenrolar dos fatos. (NUÑEZ, 2003 apud IKEDA; VELUDO-DE-OLIVEIRA; CAMPOMAR, 2006).

\section{b) Parte 2: Imersão Focal}

Após a imersão inicial, a imersão focal foi realizada na aula 2, na qual a professora discutiu o caso com os alunos. Cada caso apresentado nas disciplinas de Resolução de Casos I e II é trabalhado em duas etapas. Na primeira aula há uma apresentação do caso por um palestrante convidado, que traz a contextualização, informações e dilemas sobre o caso. Já na segunda aula, discute-se a resolução do caso, isto é, as respostas dos alunos sobre os dilemas apresentados pelos palestrantes convidados.

Para a segunda etapa do estudo observacional, foram traçados alguns focos de observação, com isso foi traçado um formato de observação, focando na análise dos pontos mais relevantes para o estudo.

Episódio: Aula de Resolução de Casos - Discussão do Caso Vivo Santa Dose

Data/Horário: 06 de maio de 2016/ Hora: $10 \mathrm{~h}$ às $11 \mathrm{~h} 40$

Participantes: Alunos da graduação em Administração e professora

Local: Faculdade FIA de Administração

1. Temas principais - Resumo do que acontece no episódio etc.

No dia da discussão do caso, todos os grupos devem entregar um relatório com as respostas ao dilema, seguindo uma estrutura passada pela professora no início do semestre. Entretanto, um grupo apresenta a resolução do caso. No início do semestre foram definidos os grupos que ficariam responsáveis pela apresentação de cada um dos casos estudados durante o semestre. Cada grupo tem uma semana para se preparar para essa apresentação. Os demais alunos não apresentam o caso, mas participam ativamente das discussões.

O grupo responsável pelo caso Santa Dose começa fazendo uma apresentação de informações complementares para contextualização, nesse caso, em específico, informações sobre a construção da marca, inovações do produto e comparação com os concorrentes. A professora e uma aluna fazem interação durante a apresentação.

Depois da apresentação prévia sobre a empresa, os alunos responsáveis pela apresentação do caso dedicam-se a responder as questões propostas pela palestrante. O grupo apresenta para a sala suas repostas e sugestões que poderiam ser adotadas pela empresa. 
2. Postura do professor - Resumo de como ele media as discussões e estimula o debate.

A professora faz comentários durante a apresentação dos alunos, resgata alguns pontos do caso, informações importantes para embasar algumas respostas. Ela estimula os demais grupos a participarem da discussão, expondo suas ideias. Aos poucos a professora vai convidando cada um dos alunos a darem suas contribuições. Durante as discussões a professora traz informações adicionais sobre o caso e novas alternativas que estimulam a reflexão dos alunos sobre os as possíveis tomadas de decisão, buscando fazer um "link" com conteúdos teóricos vistos ao longo do curso de graduação. A professora também traz informações sobre outros casos de sucesso, exemplificando as alternativas que a empresa poderia utilizar.

Os alunos vão trazendo suas ideias para discussão conjunta, durante essa troca de ideias a professora vai fazendo algumas intervenções, dizendo que algumas das sugestões feitas pelos alunos precisariam ter mais embasamento teórico e fundamentação em dados, para uma análise crítica da situação. A professora ainda ressalta que sentiu falta de maior aprofundamento e análise para desenho das alternativas possíveis para resolução dos dilemas enfrentados pela empresa. Mas também diz que surgiram ideias muito interessantes.

3. Postura do aluno em relação a participação - Resumo do envolvimento e engajamento

Os demais alunos que não estão participando da apresentação do caso começam com suas contribuições expondo suas ideias para os dilemas enfrentados pela empresa. Inicialmente a participação dos alunos se dá conforme a professora os chama para a discussão, posteriormente, a interação dos alunos começa a ser espontânea conforme a discussão avança. Percebe-se nitidamente a empolgação de alguns alunos em expor suas ideias.

Com o desenrolar da discussão, cada aluno expõe seus pontos de vistas e debate suas reflexões com os demais colegas. Nos pontos em que há discordância entre alguns pontos de vistas, os alunos discutem sobre os prós e contras de cada alternativa. As contribuições e participação dos alunos aumentam cada vez mais com o avanço da discussão.

4. Entendimento sobre a dinâmica.

Com a imersão focal, foi possível observar como se dá o processo de aprendizagem sob uma abordagem construtivista, na qual os estudantes devem estar capacitados para inovar e desenvolver um pensamento construtivo. (BONO, 2000 apud COTO; NETO; PACHECO, 2009).

5. Percepção dos alunos sobre a utilidade do Método de Caso.

Nesta última etapa foi analisada a percepção dos alunos quanto à utilização da metodologia de casos como ferramenta de ensino-aprendizagem. O questionário aplicado aos alunos da graduação continha 16 questões fechadas e estruturadas em uma escala intervalar de 1 a 10, sendo que, quanto mais próximo de 1 , menor era a concordância dos alunos em relação às afirmações feitas e, quanto mais próximo de 10, maior era o nível de concordância. Em uma análise geral dos dados coletados, foram utilizadas técnicas de estatística descritiva, objetivando analisar a dispersão, maiores ocorrências e variâncias entre os dados. A tabela 1 traz os desvios padrão, variância, mediana e moda para cada umas das questões. 
Tabela 1: Estatística descritiva - questionário com alunos da graduação FIA.

\begin{tabular}{c|c|c|c|c|c}
\hline Questões Fechadas & Desvio Padrão & Variância & Média & Mediana & Moda \\
\hline $\mathbf{1}$ & 1,94 & 3,75 & 8,20 & 8,00 & 10 \\
\hline $\mathbf{2}$ & 1,52 & 2,32 & 8,43 & 9,00 & 10 \\
\hline $\mathbf{3}$ & 1,41 & 1,99 & 8,70 & 9,00 & 10 \\
\hline $\mathbf{4}$ & 1,53 & 2,33 & 8,70 & 9,00 & 10 \\
\hline $\mathbf{5}$ & 1,55 & 2,39 & 8,67 & 9,00 & 10 \\
\hline $\mathbf{6}$ & 1,71 & 2,94 & 8,29 & 9,00 & 9 \\
\hline $\mathbf{7}$ & 1,32 & 1,75 & 9,05 & 10,00 & 10 \\
\hline $\mathbf{8}$ & 1,65 & 2,74 & 8,83 & 9,00 & 10 \\
\hline $\mathbf{9}$ & 1,97 & 3,88 & 8,75 & 10,00 & 10 \\
\hline $\mathbf{1 0}$ & 1,40 & 1,96 & 9,01 & 10,00 & 10 \\
\hline $\mathbf{1 1}$ & 1,67 & 2,80 & 8,27 & 8,00 & 10 \\
\hline $\mathbf{1 2}$ & 1,30 & 1,68 & 8,83 & 9,00 & 10 \\
\hline $\mathbf{1 3}$ & 1,76 & 3,09 & 8,45 & 9,00 & 9 \\
\hline $\mathbf{1 4}$ & 1,73 & 2,99 & 8,40 & 9,00 & 10 \\
\hline $\mathbf{1 5}$ & 2,04 & 4,15 & 7,92 & 8,00 & 10 \\
\hline $\mathbf{1 6}$ & 2,40 & 5,75 & 7,20 & 7,50 & 10 \\
\hline
\end{tabular}

Fonte: elaborado pela autora.

Com o desvio padrão e a variância torna-se possível analisar a dispersão dos dados em relação à média. Quanto maior a variância e o desvio padrão, maior a dispersão entre os dados e mais longe eles estão em relação ao valor esperado. Com isso, podem-se observar em cada uma das questões que os dados coletados não apresentam grandes variações entre si.

Por meio da estatística descritiva, pode-se analisar que para todas as questões houve certa concordância dos alunos em relação às afirmações realizadas. Essa constatação fica mais fácil de ser observada quando os dados são colocados em desenho esquemático (figura 2).

Na representação gráfica (figura 2), as questões estão apresentadas como X1; X2... X16 e a escala de concordância de 1 a 10 está traçada na linha vertical. A análise gráfica por meio do Box Plot "[...] utiliza cinco medidas estatísticas: valor mínimo, valor máximo, mediana, primeiro e terceiro quartil da variável quantitativa. Este conjunto de medidas oferece a ideia da posição, dispersão, assimetria, caudas e dados discrepantes.” (GUEDES et al., 2005, p. 44). Com essa representação esquemática, é possível visualizar que não houve grandes dispersões entre as respostas para cada uma das questões, indicando pouca variabilidade na escala de concordância. Isso revela que a maioria dos alunos concordou com as proposições teóricas feitas com base na literatura e que foram aplicadas no questionário, com objetivo de avaliar as opiniões e percepção dos alunos em relação a metodologia construtivista baseada em estudos de casos. 
Figura 2: Box Plot - Concordância das respostas dos alunos em cada questão.

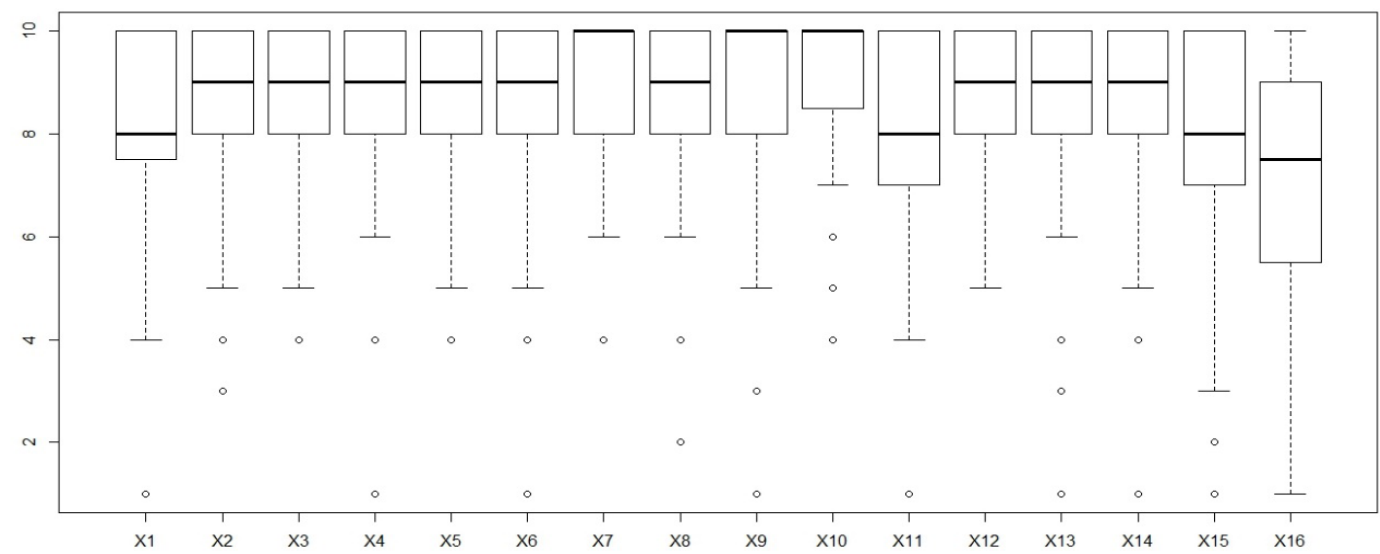

Fonte: elaborado pela autora.

Como meio de facilitar o processo de análise dos dados, a escala do questionário delimitada entre 0 a 10 foi dividida em cinco grupos, de acordo com os níveis de concordância, sendo que o grupo 1 e 2 indica baixo nível de concordância, e o grupo 9 e 10 indica maior nível de concordância dos alunos em relação às afirmações feitas no questionário. Dessa forma, as respostas foram classificadas dentro da configuração exposta na tabela 2.

Tabela 2: Agrupamento da escala de concordância em cinco macrogrupos.

\begin{tabular}{c|c}
\hline Escala de Concordância & Grupos \\
\hline 1 & $\mathbf{1}$ e 2 \\
\hline 2 & $\mathbf{1}$ e 2 \\
\hline 3 & 3 e 4 \\
\hline 4 & 3 e 4 \\
\hline 5 & 5 e 6 \\
\hline 6 & 5 e 6 \\
\hline 7 & 7 e 8 \\
\hline 8 & 7 e 8 \\
\hline 9 & 9 e 10 \\
\hline 10 & 9 e 10 \\
\hline
\end{tabular}

Fonte: elaborado pela autora.

Obteve-se um total de 84 questionários respondidos. O apêndice 3 mostra a tabulação dos dados coletados. Ao final, foi possível elaborar a tabela 3 e a figura 3 , que trazem a representação tabular e gráfica dos percentuais de respostas de cada questão atribuídos para cada um dos cinco grupos de concordância utilizados para facilitar o processo de análise. Na tabela 3 também foram descritas as variáveis analisadas em cada questão aplicada no questionário. 
Tabela 3: Percentuais de respostas por grupos de análise - questionário com alunos da graduação FIA.

\begin{tabular}{|c|c|c|c|c|c|}
\hline \multirow[b]{2}{*}{ Questões Fechadas \& Variável Analisada } & \multicolumn{5}{|c|}{$\begin{array}{l}\text { Percentual de Respostas por } \\
\text { grupos de análise }\end{array}$} \\
\hline & 1 e 2 & 3 e 4 & 5 e 6 & 7 e 8 & 9 e 10 \\
\hline 1 - Comparação de abordagens: Tradicional x Constritivista & $2 \%$ & $2 \%$ & $10 \%$ & $38 \%$ & $48 \%$ \\
\hline 2 - Comparação de abordagens: Tradicional x Constritivista & $0 \%$ & $2 \%$ & $7 \%$ & $38 \%$ & $52 \%$ \\
\hline 3 - Postura do aluno diante da abordagem construtivista & $0 \%$ & $1 \%$ & $6 \%$ & $31 \%$ & $62 \%$ \\
\hline 4 - Postura do aluno diante da abordagem construtivista & $1 \%$ & $1 \%$ & $4 \%$ & $33 \%$ & $61 \%$ \\
\hline 5 - Desenvolvimento do aluno com a utilização do método de caso & $0 \%$ & $2 \%$ & $10 \%$ & $24 \%$ & $64 \%$ \\
\hline 6 - Aprendizagem individual com a utilização do método de caso & $1 \%$ & $1 \%$ & $13 \%$ & $31 \%$ & $53 \%$ \\
\hline 7 - Vantagens das discussões em grupo & $0 \%$ & $2 \%$ & $1 \%$ & $24 \%$ & $72 \%$ \\
\hline 8 - Integração entre teoria e prática & $2 \%$ & $1 \%$ & $2 \%$ & $24 \%$ & $70 \%$ \\
\hline 9 - Importância da disciplina Resolução de Casos na Administração & $1 \%$ & $4 \%$ & $11 \%$ & $11 \%$ & $74 \%$ \\
\hline 10 - Vantagens da utilização do método de estudo de caso vivo & $0 \%$ & $1 \%$ & $7 \%$ & $17 \%$ & $75 \%$ \\
\hline 11 - Vantagens da utilização do método de estudo de caso de Harvard & $1 \%$ & $1 \%$ & $11 \%$ & $38 \%$ & $49 \%$ \\
\hline 12 - Proximidade das situações vividas no ambiente organizacional & $0 \%$ & $0 \%$ & $6 \%$ & $24 \%$ & $70 \%$ \\
\hline 13 - Efetividade do aprendizado com a utilização de casos para ensino & $2 \%$ & $2 \%$ & $1 \%$ & $37 \%$ & $57 \%$ \\
\hline 14 - Desenvolvimento da capacidade de análise com o método de caso & $1 \%$ & $4 \%$ & $7 \%$ & $32 \%$ & $56 \%$ \\
\hline 15 - Capacidade para detectar problemas & $2 \%$ & $4 \%$ & $14 \%$ & $33 \%$ & $46 \%$ \\
\hline 16 - Colaboração do aluno no processo de aprendizagem & $5 \%$ & $8 \%$ & $20 \%$ & $32 \%$ & $35 \%$ \\
\hline
\end{tabular}

Fonte: elaborado pela autora.

Figura 3: Representação gráfica dos percentuais de respostas, por grupos de análise, para as questões fechadas do questionário com alunos da graduação FIA.

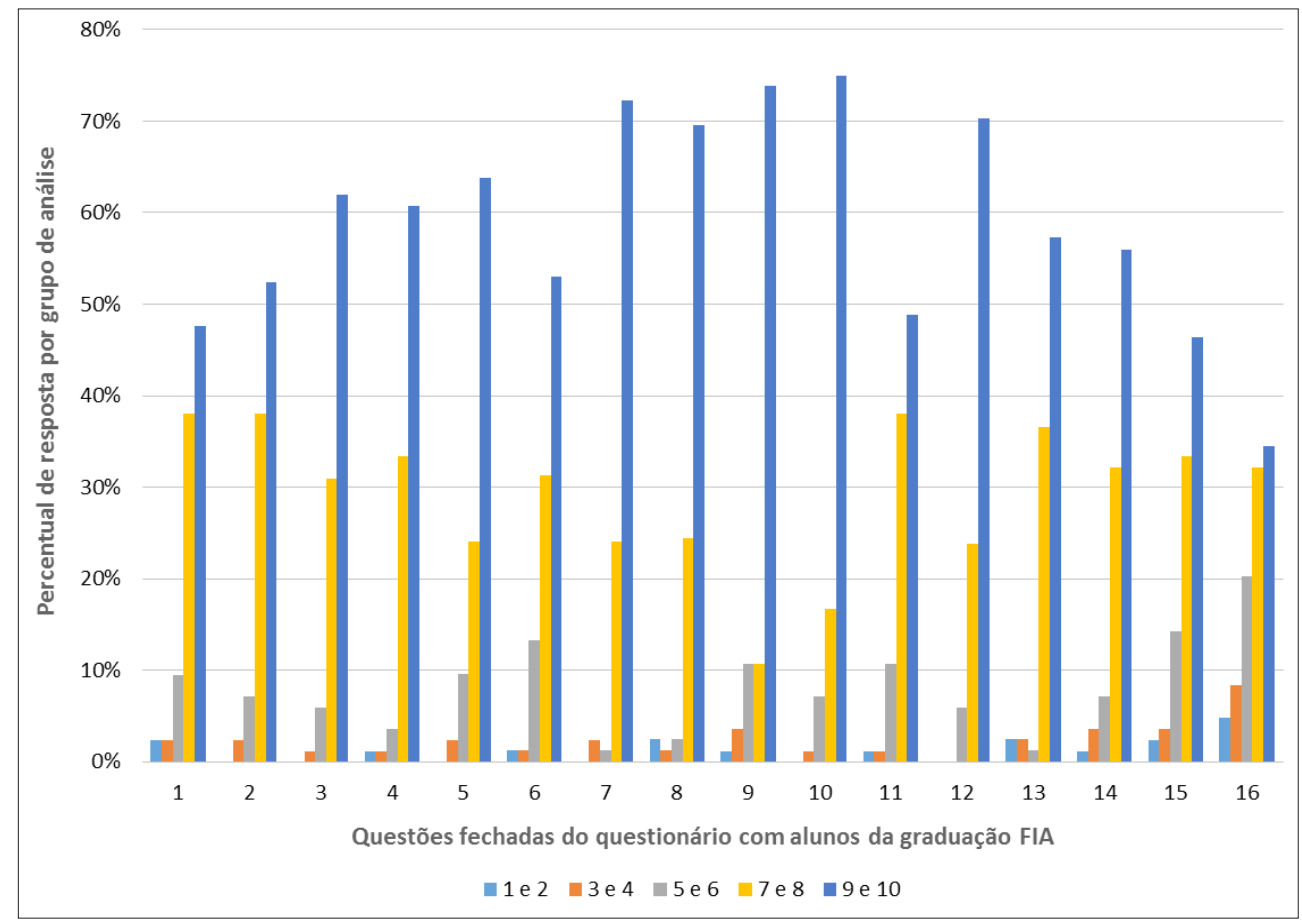

Fonte: elaborado pela autora. 
Com os resultados obtidos, é possível estruturar a análise de percepção dos alunos sobre alguns tópicos importantes analisados nesta pesquisa. Os resultados foram separados em algumas unidades de análise específicas para a interpretação do estudo realizado.

a) Percepção quanto à abordagem de ensino tradicional

Por meio da tabela 3 foi possível observar que o percentual de discordância dos alunos em relação à afirmação feita no questionário foi pequeno em todas as 16 questões fechadas. Segundo os autores Coto, Neto e Pacheco (2009), na metodologia tradicional o aluno é passivo durante todo processo de aprendizagem, pois o método é baseado somente na transmissão dos saberes dos professores. Esse aspecto foi abordado nas questões 1 e 2 do questionário, nas quais foram feitas comparações entre a abordagem tradicional e a construtivista, e pôde-se notar que houve grande concordância dos alunos em ambas questões.

A primeira questão afirmava que a abordagem tradicional faz com que o aluno desempenhe um papel passivo na sala de aula enquanto o professor expõe o conhecimento, ao contrário da abordagem construtivista, que faz com que o aluno desempenhe um papel mais ativo no processo de aprendizagem. Conforme é possível observar na tabela 3, nessa questão, $38 \%$ das respostas obtidas ficaram concentradas no grupo com nível de concordância entre 7 e 8, enquanto $48 \%$ das respostas apresentaram alto nível de concordância, pois ficaram concentradas no grupo 9 e 10 .

A segunda questão trouxe a afirmação de que o ensino tradicional tem como foco a aceitação e memorização do conteúdo ensinado, enquanto o foco da abordagem construtivista é a construção conjunta do conhecimento. Para essa questão o percentual de resposta no grupo 7 e 8 foi 38\%, enquanto no grupo 9 e 10 foi de $52 \%$.
Os resultados demonstram que a maioria dos alunos concorda com a visão de Nicolini (2003), que defende que a abordagem tradicionalista é baseada no recebimento, aceitação e memorização do conteúdo, impossibilitando que os alunos usem a criatividade para resolver problemas.

b) Percepção quanto à abordagem de ensino construtivista

As questões 3 e 4 trouxeram afirmações que buscaram analisar o nível de concordância dos alunos em relação à sua postura diante da abordagem construtivista. A questão três afirmava que na abordagem de ensino construtivista há um espaço maior para participação do aluno no processo de aprendizagem, o que permite que ele reflita mais sobre os conteúdos ensinados ao mesmo tempo em que proporciona um aprendizado mais ativo e colaborativo. Aqui se pôde observar alto nível de concordância dos alunos em relação a essa afirmação, em que $62 \%$ das respostas ficaram concentradas no grupo 9 e 10.

Na questão 4 foi abordada a variável da integração entre alunos e professores, que é mais efetiva no ensino construtivista, uma vez que ambos colaboram efetivamente para construção do conhecimento. A concordância dos alunos para essa questão esteve concentrada no grupo 9 e 10, com a representatividade de $61 \%$.

Esses dados revelam que houve grande concordância dos alunos quanto à teoria descrita por Lima (2003), que diz que abordagem construtivista é a que melhor propicia um aprendizado mais ativo, reflexivo, colaborativo.

Analisando algumas características do método estudo de caso, as questões 6 e 7 investigam a percepção dos alunos quanto ao processo de aprendizagem individual e os benéficos das discussões em grupo com a utilização de casos para ensino. 
A aprendizagem individual no método de caso é baseada na discussão em grupos, o que faz com que o aluno participe mais das discussões na sala de aula e aumente sua contribuição. Esse é o conceito que foi abordado na questão 6, na qual 53\% das respostas obtidas no questionário ficaram agrupadas entre os níveis de concordância 9 e 10 e 31\% entre 7 e 8.

A questão 7 analisou os benefícios das discussões em grupo, que permitem que o aluno amplie sua visão sobre um determinado problema estudado e mapeie melhor as alternativas de decisão sobre ele. Nessa questão o nível de concordância dos alunos teve representação significativa no grupo 9 e 10, com $72 \%$ das repostas obtidas.

A literatura evidenciada por Roesch (2007) traz que o método de caso é o que melhor possibilita o alinhamento entre teoria e prática, e a integração entre a sala de aula e a vivência no mundo empresarial, que é muito necessária em um curso de administração. Com as respostas obtidas, pôde-se observar que há grande concordância dos alunos em relação a essa teoria.

c) Percepção quanto à utilização de casos para ensino

Conforme conceitos apresentados pela literatura de Corey (1998), a utilização de casos contribui fortemente para o desenvolvimento de competências gerencias importantes no ambiente organizacional, como a capacidade de identificação e definição dos problemas, coleta e interpretação de dados relevantes, formulação de estratégias, tomadas de decisões e trabalho em grupo. Esse aspecto foi analisado na questão 5 , que investiga como se dá o desenvolvimento do aluno e a integração entre teoria e prática com a utilização da metodologia de casos.

O método de estudo de caso promove o desenvolvimento da capacidade da ação do aluno, uma vez que o processo de coleta de informações para resolução dos casos exige uma atitude proativa. Esse ponto é abordado na questão 5, e os resultados obtidos revelam alta concordância dos alunos - 64\% das repostas ficaram concentradas no grupo 9 e 10 .

A questão 8 explorou a percepção dos alunos sobre a integração entre a teoria e prática proporcionada pelas disciplinas Resolução de Casos I e II. Pôde-se observar que a maioria considera essa disciplina importante no curso, já que $70 \%$ das respostas ficaram concentradas no grupo 9 e 10.

As questões 10 e 11 buscaram capturar a impressão dos alunos no que se refere às vantagens oferecidas pelo método de estudo caso considerando a tipologia de casos vivos e de casos clássicos de Harvard no processo de ensino-aprendizagem. Conforme aponta Nuñez (2003 apud IKEDA; VELUDO-DEOLIVEIRA; CAMPOMAR, 2006), os casos vivos têm a vantagem de poderem ser acompanhados concomitantemente ao desenrolar dos fatos, o que traz implicações positivas à aprendizagem e proporciona um aprendizado mais ativo e reflexivo, conforme apresentado na questão 13, que apresentou percentuais de concordância dos alunos em relação a essas vantagens de $37 \%$ no grupo 7 e 8 e $57 \%$ no grupo 9 e 10.

A vivência com casos reais, ainda que na sala de aula, prepara o aluno para enfrentar os futuros desafios como administrador/ gestor. A concordância dos alunos em relação às vantagens oferecidas por esse tipo de caso foi muito alta. Isso pode ser observado nas respostas da questão 10, que tiveram uma concentração de 75\% no grupo 9 e 10. Além disso, a questão 12 do questionário traz a afirmação de que a utilização de casos vivos deixa o aluno mais próximo das situações vividas no ambiente organizacional, uma vez que trazem situações que se sucederam há 
pouco tempo ou que ainda estão ocorrendo nas empresas. Observa-se que o nível de concordância dos alunos em relação a essa questão também foi alto, com representatividade de $70 \%$ no grupo 9 e 10 .

As três últimas questões do questionário com os alunos eram abertas, para que eles demostrassem livremente suas opiniões sobre a experiência com o aprendizado baseado na metodologia de casos. O processo de análise dessas questões se deu com a utilização das ferramentas de consulta do software NVivo, com as quais é possível desenhar nuvens das palavras que apareceram com maior frequência dentro das 84 respostas coletadas nos questionários, conforme representado na figura 4:

Figura 4: nuvem das palavras que apareceram com maior frequência quando perguntado sobre ter uma disciplina específica de casos na grade curricular em Administração.

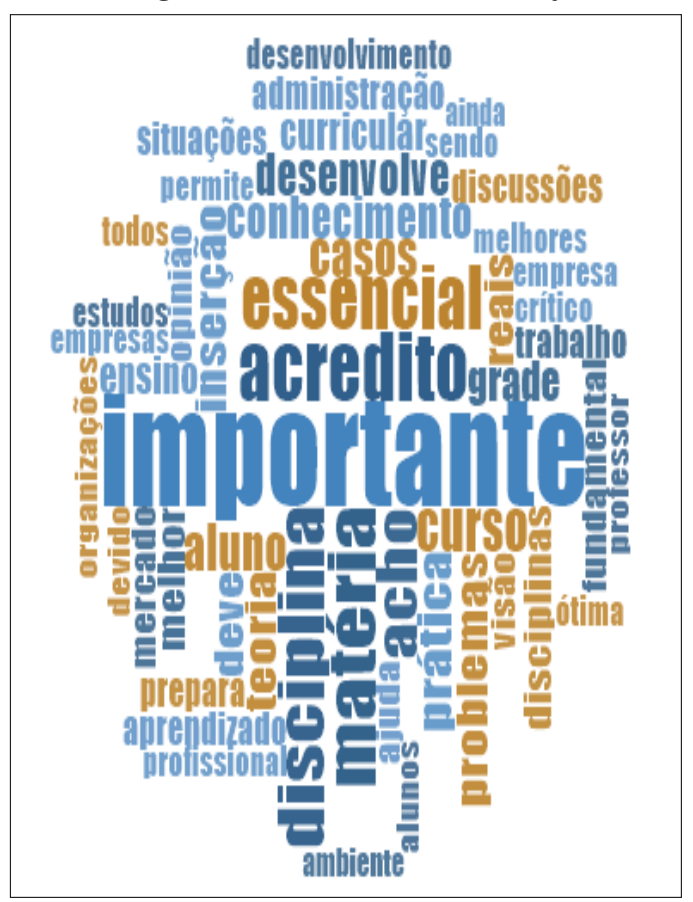

Fonte: elaborado pela autora.
Através da figura 4, pode-se observar que a palavra que mais aparece nas respostas obtidas é a palavra "importante", pois é a que está em maior destaque na nuvem de palavras apresentada. Isso indica que, ainda que a disciplina seja recente nos cursos de Administração, ela já é considerada importante na grade curricular do curso pelos alunos da amostra selecionada. Conforme aponta a literatura apresentada por Iizuka (2008), na maioria das instituições os casos são explorados de forma transversal, já que muitos deles são encontrados em livros didáticos de administração e que raramente retratam a realidade brasileira; na maioria das vezes, são preparados para confirmação de uma teoria discutida em sala, não retratando a administração de forma integrada e não trazendo para sala de aula relatos sobre os desafios, oportunidades e as situações vividas nas organizações. Nesse sentido, a disciplina de Resolução de Casos se faz importante na medida em que trata exclusivamente de casos de gestão que discutem a realidade nas organizações e buscam integrar alguns conteúdos vistos durante o curso, deixando o aluno cada vez mais próximo da realidade empresarial.

Na literatura utilizada, Roesch (2007, p. 12) destaca que "[...] o caso para ensino é um entre poucos métodos de ensino-aprendizagem que possibilita um "casamento" entre teoria e prática, tão necessário para a área de Administração.” Essa relação também é analisada na árvore de palavras originada pelas respostas dos pesquisados, apresentada na figura 5. 
Figura 5: árvore de palavras sobre como é essencial ter uma disciplina específica de casos na grade curricular em administração.

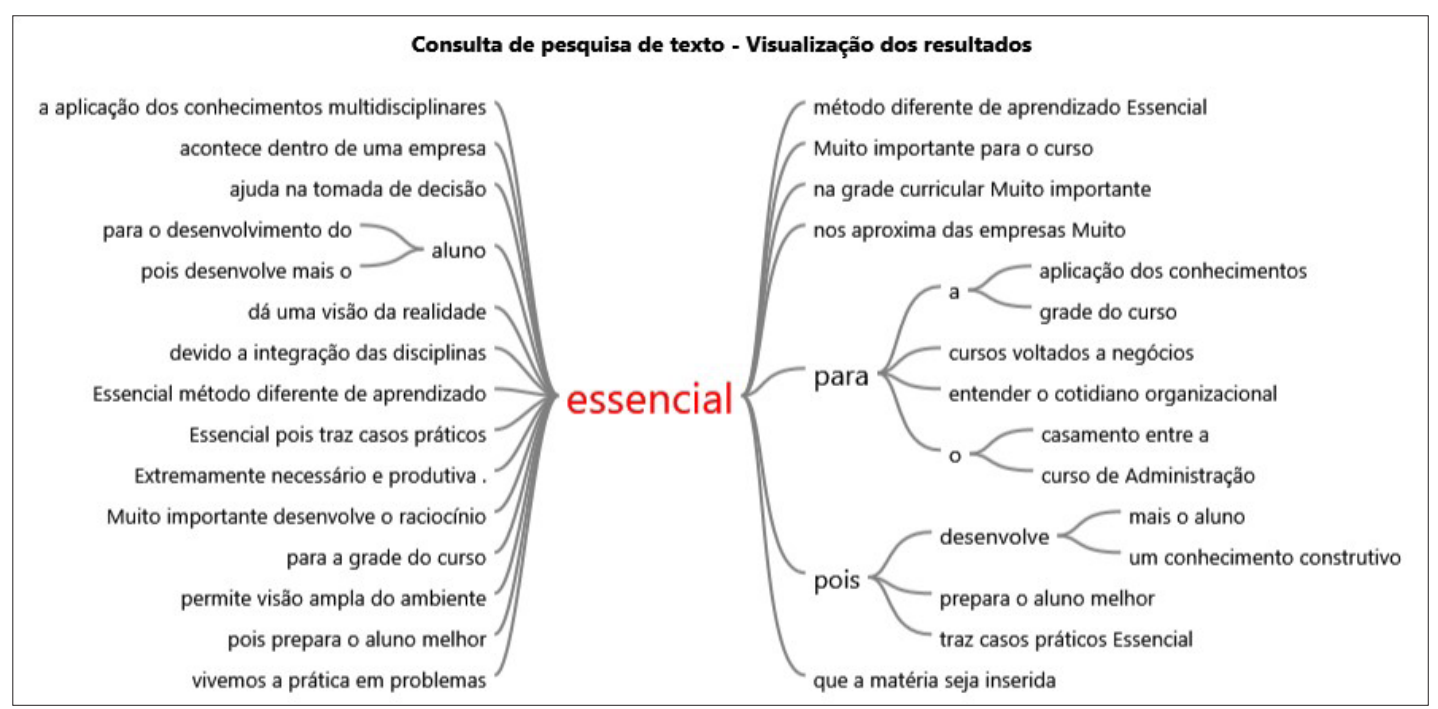

Fonte: elaborado pela autora.

Pode-se perceber, pela figura 5, que os alunos consideram a disciplina essencial, porque ela permite a aplicação dos conhecimentos adquiridos e o desenvolvimento do aluno, ao mesmo tempo em que oferece uma visão da realidade que será vivenciada no âmbito organizacional quando se tornar um executivo. A disciplina Resolução de Casos também é considerada essencial porque traz casos práticos para sala de aula, o que permite uma visão mais ampla do ambiente empresarial e promove maior integração entre as disciplinas. Nesse sentido, também é possível analisar como os pesquisados enxergam a importância da metodologia construtivista na construção de um aprendizado mais efetivo e melhor preparo para ingresso no mercado de trabalho. Com base na figura 6, percebe-se que os alunos da amostra selecionada consideram a disciplina Resolução de Casos muito importante para seu próprio desenvolvimento, para aplicação da teoria na prática, conhecimento da dinâmica empresarial e melhor entendimento sobre o mundo corporativo. Além disso, a capacidade analítica para tomada de decisão, senso crítico para resolução de problemas e capacidade para realização de trabalho em grupo, são habilidades muito exigidas no ambiente empresarial. Pelos dados coletados pode-se depreender que a abordagem construtivista baseada na resolução de casos promove o desenvolvimento dessas habilidades tão requeridas no mercado de trabalho.

A literatura apresentada por Corey (1998) revela que a utilização de casos contribui fortemente para o desenvolvimento de competências gerenciais importantes no ambiente organizacional. Com os dados coletados, percebe-se que palavras como “capacidade”, “experiência”, “discussões”, "problemas”, "situações” e "saber” apareceram com frequência nas respostas dos alunos participantes da amostra. Analisando a nuvem de palavras na figura 7 pode-se visualizar de forma mais clara essa constatação. 
Figura 7: nuvem de palavras - importância das discussões dos estudos de casos na preparação do aluno antes da atuação no mundo empresarial.

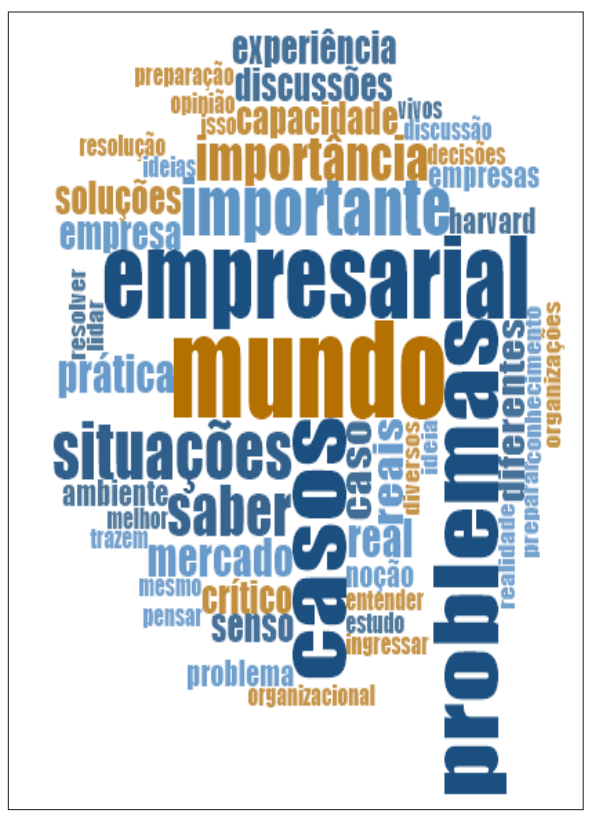

Fonte: elaborado pela autora
A teoria apresentada por Ellet (2001) defende que a prática de trabalhar na resolução de casos que retratam a realidade vivenciada no mundo empresarial oferece aos estudantes de Administração uma experiência prática equivalente à que os médicos e cientistas desfrutam em laboratórios de pesquisa. Na figura 7 nota-se que as palavras "mundo empresarial” apareceram com frequência nas repostas dos pesquisados.

Com a árvore de palavras representada na figura 8 pode-se ter uma visão das percepções dos alunos sobre como a metodologia de casos os prepara para atuação no mundo empresarial.

Figura 8: árvore de palavras sobre a importância das discussões dos estudos de caso na preparação do aluno antes da atuação no mundo empresarial.

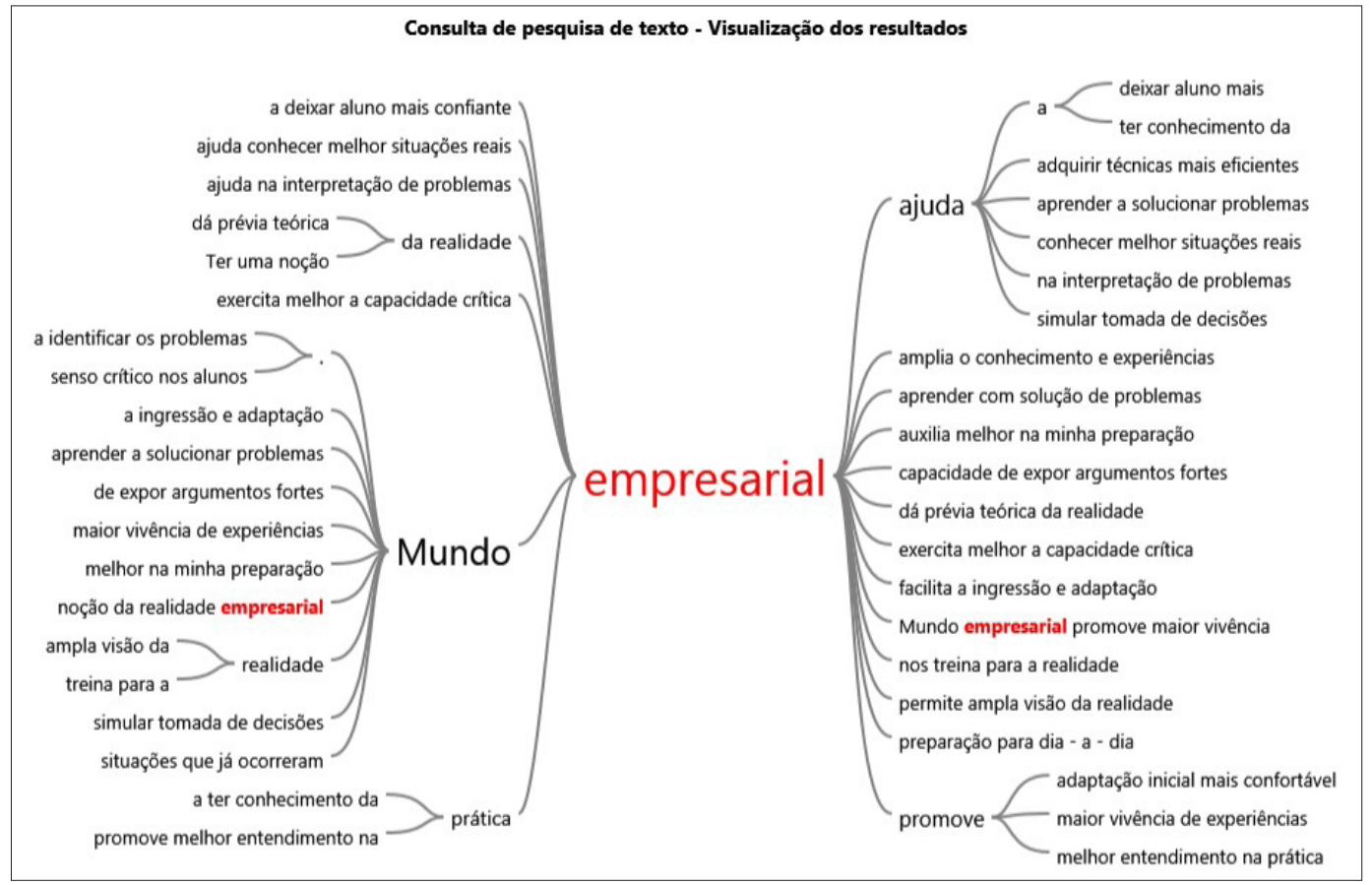

Fonte: elaborado pela autora. 
É possível observar na figura 8 que os alunos da amostra selecionada consideram importante as discussões dos estudos de casos, pois os ajudam a conhecer melhor as situações reais do mundo empresarial, aprender a solucionar problemas e simular o processo de tomada de decisão. Além disso, essas discussões promovem uma adaptação mais confortável ao ingressar no mundo empresarial, deixando o aluno mais confiante, e também oferecem a oportunidade de vivenciar experiências práticas do ambiente organizacional. Dos dados coletados, depreende-se ainda que as discussões dos casos exercitam a capacidade crítica e a capacidade de interpretação de problemas, os quais muitas vezes não estão apresentados de forma clara, tão requerido no mundo empresarial.

Com isso, evidencia-se que algumas das vantagens da utilização do método de caso como ferramenta de ensino estão refletidas no desenvolvimento da capacidade de ação, aprendizagem individual baseada na discussão em grupos e formação de esquema próprio de resolução de problema, segundo Oliveira, Muritiba e Limongi-França (2004). Por meio dos dados coletados, percebe-se que essas vantagens se comprovam, uma vez que os alunos se sentem mais bem preparados e confiantes para atuação no ambiente corporativo. Nesse sentido, a ferramenta atua com o exercício da capacidade crítica, desenvolvimento da capacidade de argumentação e critérios de análise.

A última questão do questionário aplicado - Pela sua experiência na disciplina Resolução de Casos, você faria outra disciplina nesse formato? - buscou interpretar o sentimento dos alunos quanto ao método construtivista empregado na disciplina, para analisar os pontos positivos e negativos advindos da utilização dessa metodologia. A nuvem de palavras representada pela figura 9 traz de forma ilustrativa a representação das
50 palavras mais frequentes dentre as repostas da amostra selecionada:

Figura 9: nuvem de palavras - se os alunos fariam outra disciplina baseada na metodologia de casos.

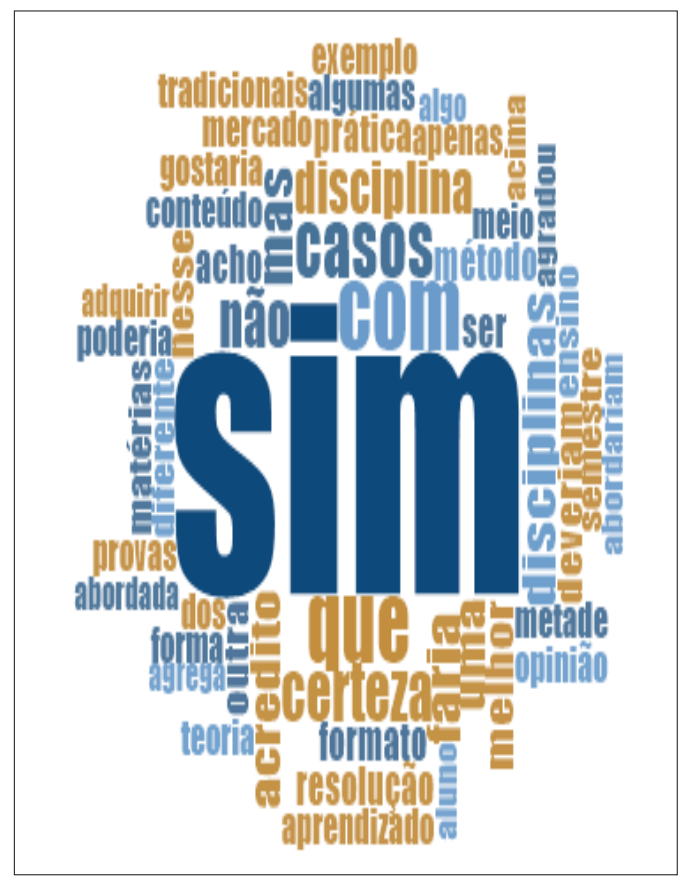

Fonte: elaborado pela autora.

Com essa representação (figura 9), fica claro que a experiência com a metodologia de ensino construtivista foi positiva para a maioria dos alunos. Percebe-se que a palavra “sim” ganhou destaque entre as respostas obtidas. Além disso, também se pôde depreender que a disciplina Resolução de Casos teve uma contribuição importante para o aprendizado dos alunos da amostra selecionada, fazendo com que eles adquirissem boas experiências, muitas das quais poderão facilmente ser aplicadas no ambiente organizacional.

Da figura 10 podem ser extraídos alguns motivos que levariam os alunos a cursar outras disciplinas baseadas na metodologia construtivista: 
Figura 10: Árvore de palavras sobre o que levaria os alunos da amostra a cursarem outras disciplinas baseadas na metodologia construtivista.

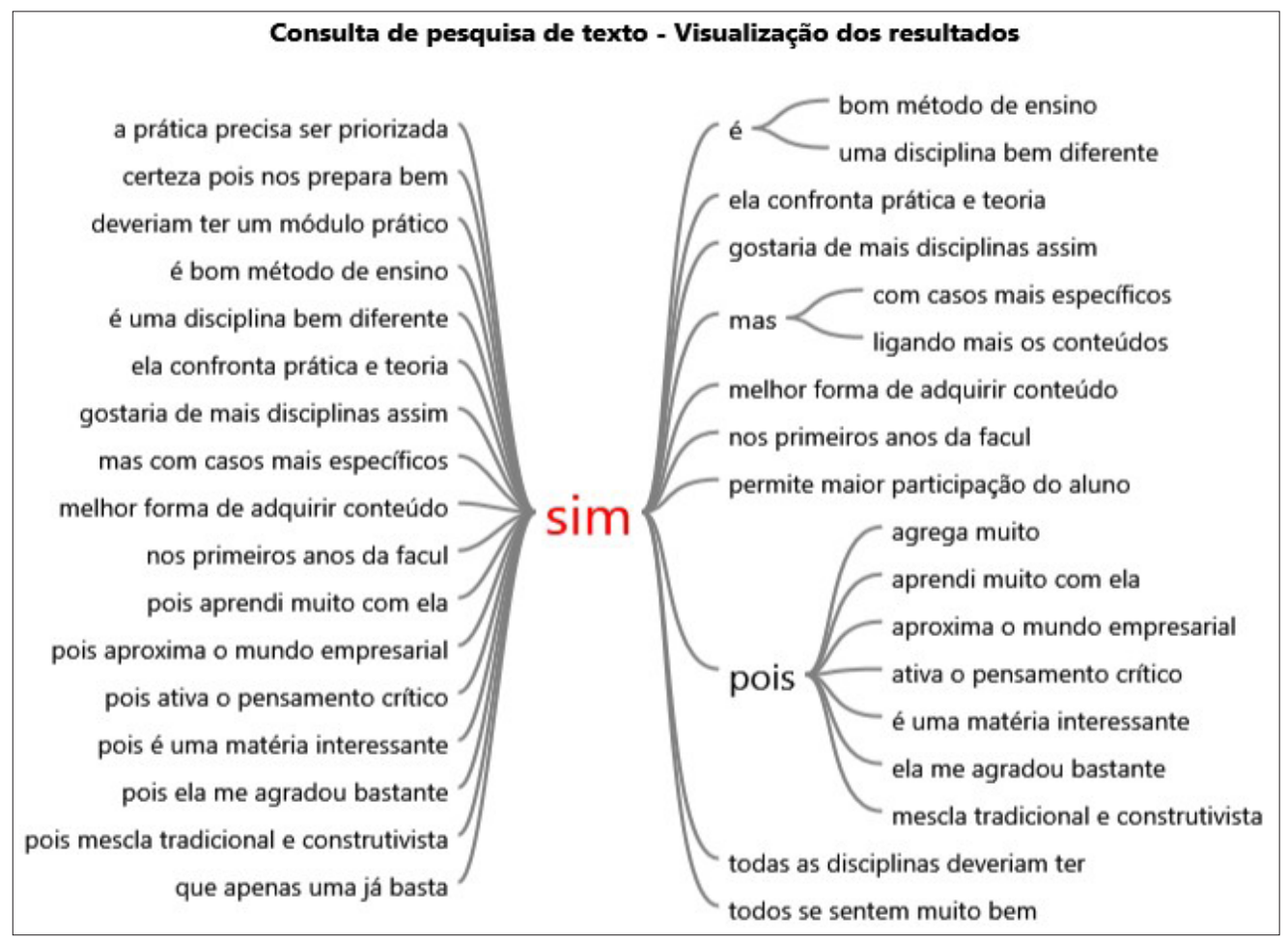

Observa-se na figura 10 que muitos são os fatores que levariam os alunos a cursarem outras disciplinas no formato da disciplina de Resolução de Casos. Por meio dos dados coletados, evidencia-se que a abordagem construtivista, baseada na metodologia de casos, confronta a teoria através de meios práticos de aprendizado, que buscam ativar e desenvolver a capacidade de análise crítica e argumentação dos estudantes, deixando-os mais próximos da realidade organizacional. É interessante notar, também, que há o interesse por parte dos alunos para que outras disciplinas sejam ministradas nesse mesmo formato. Além disso, os alunos consideram que a disciplina facilita o aprendizado, na medida em que oferece uma forma melhor de adquirir os conhecimentos necessários para se obter sucesso no mercado de trabalho.
Embora existam muitos fatores positivos que ressaltam a efetividade do aprendizado apresentado pela metodologia de casos, os dados coletados também revelam algumas sugestões para melhor aplicação deste método, como, por exemplo, o uso de casos mais específicos para cada uma das áreas que englobam o curso de Administração. Com isso, faz-se importante relatar que ainda que muitos considerem a ideia de cursar outras disciplinas no mesmo formato, há algumas ressalvas para melhorar o processo: "Faria, contudo, buscando entreter mais os alunos para que os casos não se tornem cansativos.”; "Sim, mas gostaria de focar em tipos de casos mais específicos, por exemplo, financeiro, estratégia etc." e "Faria, porém, nos primeiros anos da faculdade apenas.” 


\section{Considerações finais}

Este artigo contou com uma pesquisa qualitativa, baseada em um estudo de caso único, no qual foram utilizadas múltiplas fontes de evidências com objetivo de "mergulhar" profundamente no problema de pesquisa e responder à questão do estudo de forma mais efetiva.

O estudo se propôs a analisar como o método de caso pode auxiliar a integração entre o que se ensina na sala de aula e o que se vivencia no ambiente organizacional. Para atingir esse objetivo geral, foram criados alguns objetivos específicos que delimitaram o escopo desta pesquisa: analisar as abordagens de ensino da administração, no que se refere ao conceito tradicionalista e ao ensino construtivista; analisar como o método de estudo de caso promove a integração entre teoria e prática, no ensino superior em Administração; analisar como o método de estudo de caso aumenta a participação e o engajamento dos alunos na sala de aula; explicar as diferentes tipologias dos casos utilizadas como método de ensino, evidenciadas na literatura; relatar experiências dos alunos e professores adquiridas com a adoção de casos como técnica de aprendizagem, no ensino superior em Administração; propor ações que viabilizem o melhor aproveitamento do método de estudo de caso como técnica de aprendizagem no ensino da Administração em Instituições de Ensino Superior (IES).

No tocante às abordagens utilizadas como método de ensino, a abordagem tradicional impossibilita que os alunos usem a criatividade para resolver problemas, desestimulando a visão crítica para a sua resolução, pois se baseia em uma metodologia que visa aceitar, receber e memorizar os conteúdos. (NICOLINI, 2003; CLOSS; ARAMBARU; ANTUNES, 2009). Em contrapartida, a abordagem construtivista visa um aprendizado mais ativo, reflexivo e colaborativo (LIMA,
2003), contribuindo para maior desenvolvimento e preparo do alunado no enfrentamento dos desafios que encontrará no mercado de trabalho. Além disso, os problemas do mundo organizacional exigem análises criteriosas para um melhor desenho das alternativas possíveis, pois análises mais críticas, com embasamento teórico e fundamentação em dados, permitem que as decisões sejam tomadas de forma mais assertiva. A abordagem construtivista é a que melhor prepara o aluno para o que se vivencia no ambiente organizacional.

No que se refere ao método de caso, ele atende ao princípio construtivista de aprendizagem e contribui significativamente para a formação do administrador. Ficou evidente no estudo que a utilização de casos contribui fortemente para o desenvolvimento de competências gerencias importantes no ambiente empresarial, promovendo maior integração entre a teoria e prática, pois desenvolve nos alunos a capacidade de identificação e definição dos problemas, coleta e interpretação de dados relevantes, formulação de estratégias, tomadas de decisões e trabalho em grupo. (COREY, 1998). Os casos vivos, por exemplo, aumentam a participação do aluno na sala de aula. Esse tipo de caso discute problemas que a empresa está enfrentando simultaneamente com o desenrolar dos fatos, ao tempo em que convida os alunos a analisar e investigar o caso de forma crítica, assumindo o papel do tomador de decisão, estimulando a criação de alternativas para resolução do problema. As alternativas são discutidas e colocadas “na mesa” nos debates em sala de aula. Essa prática permite a construção de um processo de aprendizagem ativo, no qual os alunos são mais motivados a aprender.

Foi possível notar também que a adoção da metodologia de caso no ensino da Administração trouxe contribuições positivas tanto para o professor quanto para os alunos, uma vez que o professor acaba 
interagindo mais com alunos à medida que faz a intermediação nas discussões e debates na sala de aula. Na entrevista realizada, foi dito que o professor atua como moderador, estimulando e instigando o raciocínio dos alunos; já os alunos assumem o papel de protagonistas, sendo agentes ativos no processo de aprendizagem.

Com isso, conclui-se que a metodologia de caso auxilia a integração entre o que se aprende na sala de aula e o que se vivencia no ambiente organizacional, pois proporciona aos alunos um aprendizado mais ativo e reflexivo, fazendo-os desenvolver habilidades para detecção, investigação e resolução de problemas, ampliando o campo de visão das alternativas para a tomada de decisão. Dessa forma, como proposta de ação para melhor aproveitamento do método de caso como ferramenta de ensino-aprendizagem no ensino superior em Administração, fica registrada a utilização de casos que promova maior integração entre as disciplinas estudadas durante o curso.

Como limitações deste estudo, ficam relatadas:

- O objeto de estudo desta pesquisa tem objetivos diferentes dos da maioria das escolas de ensino superior; as salas comportam poucos alunos e isso permite maior efetividade na utilização do método de caso. Os resultados aqui obtidos aplicam-se a faculdades com modelos de gestão semelhantes ao da Faculdade FIA de Administração;

- A pesquisa baseou-se em um estudo de caso, não criando oportunidade para generalizações a respeito dos resultados obtidos.

- Como sugestões para novos estudos, ficam apontados:
- Estudos sobre a efetividade da aplicação do método de caso em outras instituições de ensino superior que têm um modelo de gestão diferenciado em relação à Faculdade FIA de Administração;

- Estudos sobre a inserção do método de caso em instituições de ensino superior que não utilizam essa ferramenta como técnica de ensino-aprendizagem.

\section{Referências}

CLOSS L. Q.; ARAMBURU, J. V.; ANTUNES, E. D. Produção científica sobre o ensino em Administração: uma avaliação envolvendo o enfoque do paradigma da complexidade. Revista Eletrônica de Gestão Organizacional, Recife, v. 7, n. 2, p. 150-169, maio/ago. 2009.

COREY, E. R. Case method teaching. Boston: HBS Publishing, 1998.

COTO, G. C.; NETO, L. M.; PACHECO, A. S. Criatividade dentro da educação: um estudo de caso do Curso de Administração da UFSC - Universidade Federal de Santa Catarina. Revista de Ciências da Administração, Florianópolis, v. 11, n. 24, p. 221-245, maio/ago. 2009.

ELLET, W. Manual de estudo de caso: como ler, discutir e escrever casos de forma persuasiva. Porto Alegre: Bookman, 2008.

FREIRE, P. Pedagogia da autonomia: saberes necessários à prática educativa. Rio de Janeiro: Paz e Terra, 2014.

GUEDES, T. A. et al. Projeto de ensino: aprender fazendo estatística. 2005. Disponível em: <http://www.each.usp. br/rvicente/Guedes_etal_Estatistica_ Descritiva.pdf>. Acesso em: 19 maio 2016. 
IIZUKA, E. S. O método do Caso de Harvard: reflexões sobre sua pertinência ao contexto brasileiro. In: ENCONTRO DA ASSOCIAÇÃO NACIONAL DE PÓS-GRADUAÇÃO E PESQUISA EM ADMINISTRAÇÃO, 32., 2008, Rio de Janeiro. Anais... Rio de Janeiro: ANPAD, 2008. p. 1-14.

IKEDA, A. A.; VELUDO-DE-OLIVEIRA, T. M.; CAMPOMAR, M. C. O caso como estratégia de ensino na área de Administração. Revista de Administração da USP, São Paulo, v. 41, n. 2, p. 147-157, 2006.

A tipologia do método do caso em Administração: usos e aplicações. Organizações \& Sociedade, Salvador, v. 12, n. 34, p. 141-159, 2005.

LIMA, M. C. Estudos de casos hipertextuais: rumo a uma inovação no método Harvard de ensino de gestão. Revista Administração Contemporânea, Rio de Janeiro, v. 7, n. 3, p. 88-99, 2003.

\section{MASETTO, M. T. Competência pedagógica} do professor universitário. São Paulo: Summus, 2012.

MENEZES, M. A. de A. Do método do caso ao case: a trajetória de uma ferramenta pedagógica. Educação e Pesquisa, São Paulo, v. 35, n. 1, p. 129-143, jan./abr. 2009.

NICOLINI, A. Qual será o futuro das fábricas de administradores? Revista RAE, São Paulo, v. 43, n. 2, p. 44-54, 2003.

NUÑEZ, A. M. O estudo de casos: um enfoque cognitivo. México, DF: Trillas, 2003.

OLIVEIRA, P. M. de; MURITIBA, S. N.; LIMONGI-FRANÇA, A. C. Resolução competitiva de casos no ensino de gestão de pessoas: caso de ensino: diagnóstico de gestão de pessoas da Investware. In: ENCONTRO ANUAL DA ASSOCIAÇÃO
NACIONAL DE PÓS-GRADUAÇÃO E PESQUISA EM ADMINISTRAÇÃO, 28., 2004, Curitiba. Anais... Curitiba: ANPAD, 2004. p. 1-16.

FIA. Fundação Instituto de Administração. Ranking. Disponível em: <http://www3. fia.com.br/ConhecaFIA/Ranking/Paginas/ Ranking.aspx>. Acesso em: 27 mai. 2016.

ROESCH, S. M. A. O papel da pesquisa de campo na construção de casos para ensino. In: ENCONTRO DA ASSOCIAÇÃO NACIONAL DE PÓS-GRADUAÇÃO E PESQUISA EM ADMINISTRAÇÃO, 31., 2007, Rio de Janeiro. Anais... Rio de Janeiro: ANPAD, 2007. 1 CD-ROM.

ZANNI, P. P.; SALATI MARCONDES, G. H.; MARIOTTO, F. L. Z. Para que servem os estudos de caso único? In: ENCONTRO DA ASSOCIAÇÃO NACIONAL DE PÓS-GRADUAÇÃO E PESQUISA EM ADMINISTRAÇÃO, 35., 2011, Rio de Janeiro. Anais... Rio de Janeiro: ANPAD, 2011. p. 1-16. 